\title{
Influencing Factors in Acoustic Emission Detection: A Literature Review Focusing on Grain Angle and High/Low Tree Ring Density of Scots Pine
}

\author{
Giulia Boccacci ${ }^{1}$, Francesca Frasca ${ }^{1}$ (D) Chiara Bertolin ${ }^{2}$ (D) and Anna Maria Siani ${ }^{1, *}$ (ID) \\ 1 Department of Physics, Sapienza University of Rome, Piazzale Aldo Moro 5, 00185 Rome, Italy; \\ boccacci.1766495@studenti.uniroma1.it (G.B.); f.frasca@uniroma1.it (F.F.) \\ 2 Department of Mechanical and Industrial Engineering, Norwegian University of Science and Technology, \\ Richard Birkelands vei 2B, Gløshaugen, 7491 Trondheim, Norway; chiara.bertolin@ntnu.no \\ * Correspondence: annamaria.siani@uniroma1.it; Tel.: +39-06-4991-3479
}

check for updates

Citation: Boccacci, G.; Frasca, F.; Bertolin, C.; Siani, A.M. Influencing Factors in Acoustic Emission Detection: A Literature Review Focusing on Grain Angle and High/Low Tree Ring Density of Scots Pine. Appl. Sci. 2022, 12, 859. https://doi.org/10.3390/ app12020859

Academic Editor: Emanuela Bosco

Received: 21 December 2021

Accepted: 12 January 2022

Published: 14 January 2022

Publisher's Note: MDPI stays neutral with regard to jurisdictional claims in published maps and institutional affiliations.

Copyright: (C) 2022 by the authors. Licensee MDPI, Basel, Switzerland. This article is an open access article distributed under the terms and conditions of the Creative Commons Attribution (CC BY) license (https:// creativecommons.org/licenses/by/ $4.0 /)$.

\begin{abstract}
Among non-destructive testing (NDT) techniques applied to structural health monitoring in existing timber structures, ranging from visual inspection to more sophisticated analysis, acoustic emission (AE) is currently seldomly used to detect mechanical stresses in wooden building assets. This paper presents the results from a systematic literature review on AE NDT applied to monitor micro and macro fracture events in softwood, specifically Scots pine. This survey particularly investigates its application with respect to the tree rings density and grain angle inspection, as influencing factors well correlated with physical and mechanical characteristics of wood. The literature review was performed in a three-step process defined by the PRISMA (Preferred Reporting Items for Systematic reviews and Meta-Analyses) flow diagram, leading to the selection of 31 documents from different abstract and citation databases (Scopus, Web of Science and Google Scholar). The outcomes have highlighted how laboratory experiments, including several types of tests (tensile, cutting, compressive, etc.), were conducted in most cases, while a very limited number of studies investigated on in situ monitoring. In addition, theoretical approaches were often explored in parallel with the experimental one. It emerges that-for tree ring density studies—a multi-technique approach, which may include microscopic observations, could be more informative. Indeed, although not widely investigated, high/low tree ring density and grain angle were found as influencing factors on the AE parameters detected by the sensors, during condition and structural health monitoring experiments.
\end{abstract}

Keywords: acoustic emission; Scots pine; non-destructive techniques; grain angle; tree ring density; PRISMA; wood; softwood

\section{Introduction}

Deformation and fracture are some of the common problems affecting wood material as it is often used, nowadays as in the past, in the construction of structures and artefacts of cultural value and therefore in need of special care and conservation. Research on wood is conducted by using different non-destructive testing (NDT) techniques mainly aimed at timber grading and assessment of existing timber structures [1].

Among NDT techniques, acoustic emission (AE) has recently been used to detect mechanical stresses in existing timber structures. An overview of the application of AE on wooden materials was already provided by Baensch [2] and Ross [3]. The aim of our review is to analyse the state of the art of the AE NDT technique applied to monitor the occurrence of fracture events in softwoods, specifically Scots pine, focusing on the influence of grain angle and tree ring density on such occurrence. First, the general framework of NDT used on wood samples was initially defined by means of a preliminary survey, designed to study the influence of high/low tree ring density and grain angle direction on the outcomes obtained through the different methods. After that, the same influencing factors in relation 
to the AE parameters detected during experiments on wood samples, were investigated in a systematic literature review.

The density parameter as a focus of this work was defined as the ratio between the dry weight of wood divided by the green volume of the same wood (expressed in $\mathrm{g} / \mathrm{cm}^{3}$ ) [4] In addition, the tree ring width (TRW) was investigated, as one of the main parameters used in dendrochronology for the reconstruction of climate variability of the past (tree rings usually grow wider in warm, wet years and they are thinner in years when it is cold and dry). Finally, the wood grain angle as the angle between the wood fibre direction and the vector in the axial direction (as shown in Figure 1), was studied together with the density as influencing factors in the AE detection.
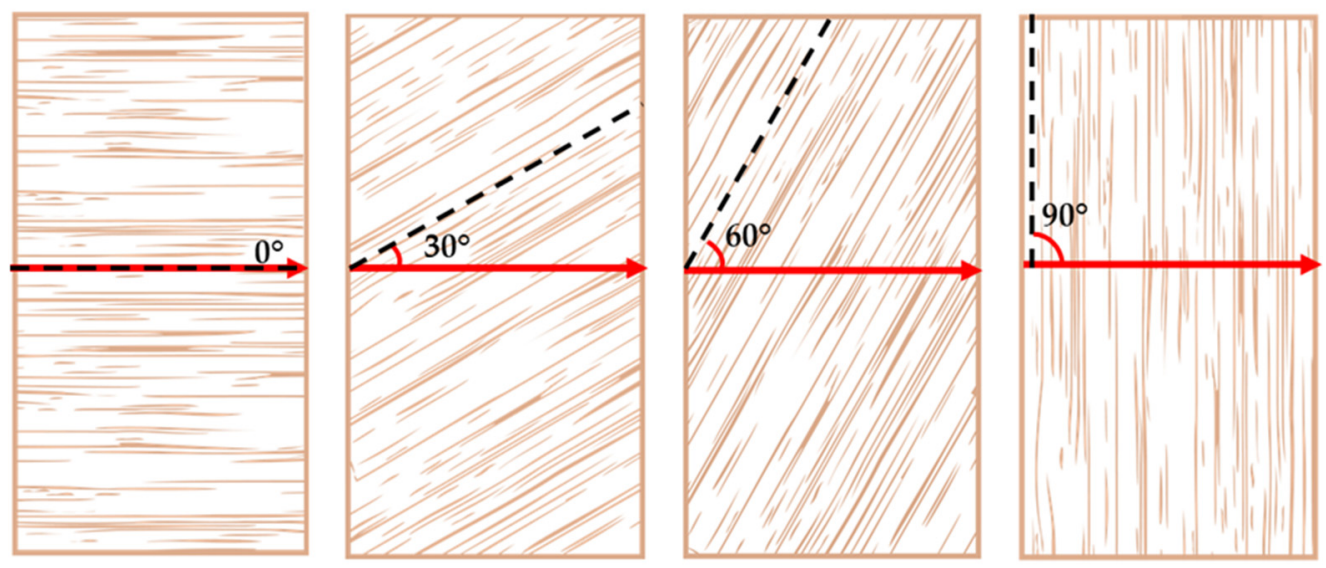

Axial direction

Figure 1. Illustration of samples with different grain angles (0-30-60-90 $)$.

The paper is structured into three sections: following the introduction, the second section (i.e., Methodology) describes the search strategy based on the three-step process that led to the screening of the documents analysed in this review. In the third section (i.e., Results and Discussion), papers were organized by outcomes and into geographical regions, year of publication and subject areas of the research. Discussion on the outcomes is provided here. Then, the last section (i.e., Conclusions) evaluates the aspects mentioned above and identifies gaps in the application of AE on structural health and condition monitoring of softwood material, that might be faced and filled in the future.

\section{Methodology}

A first step of the literature review included a preliminary survey aimed to pinpoint the most widely used non-destructive testing techniques in the study of wood samples and assets.

Then, the systematic literature review on AE NDT technique applied to monitor the occurrence of fracture events in Scots pine, was performed using a three-step process described by the PRISMA (Preferred Reporting Items for Systematic reviews and MetaAnalyses) flow diagram [5].

\subsection{Preliminary Literature Survey}

The preliminary literature survey was carried out by searching useful documents for the definition of the background within which the current research is included. The research was conducted by using the online databases Scopus, Google Scholar and Web of Science. It was conducted through five keyword combinations using the Boolean operator "AND": (1) "NDT" AND "Grain" AND "Pine", (2) "NDT" AND "Pine", (3) "NDT" AND "Softwood", (4) "NDT" AND “Grain" AND “Wood" AND “Fracture", (5) "NDT" AND "Earlywood" AND "Latewood". 
Some of the documents resulting from this search through the above-mentioned databases, and other documents of interest for a total of 13 publications, were reported in Table A2 (see Appendix A).

\subsection{Literature Review}

\subsubsection{Search Strategy and Papers Collection}

Figure 2 shows the three-step procedure entailed by PRISMA flow diagram: (i) identification; (ii) screening; (iii) inclusion. Step (i) was performed with five keyword combinations, again using the Boolean operator "AND": (1) "Acoustic Emission" AND "Grain" AND "Pine", (2) "Acoustic Emission" AND "Pine", (3) "Acoustic Emission" AND "Softwood", (4) "Acoustic Emission" AND "Grain" AND "Wood" AND "Fracture", (5) "Acoustic Emission" AND "Earlywood" AND "Latewood".

\section{Identification of studies via databases}

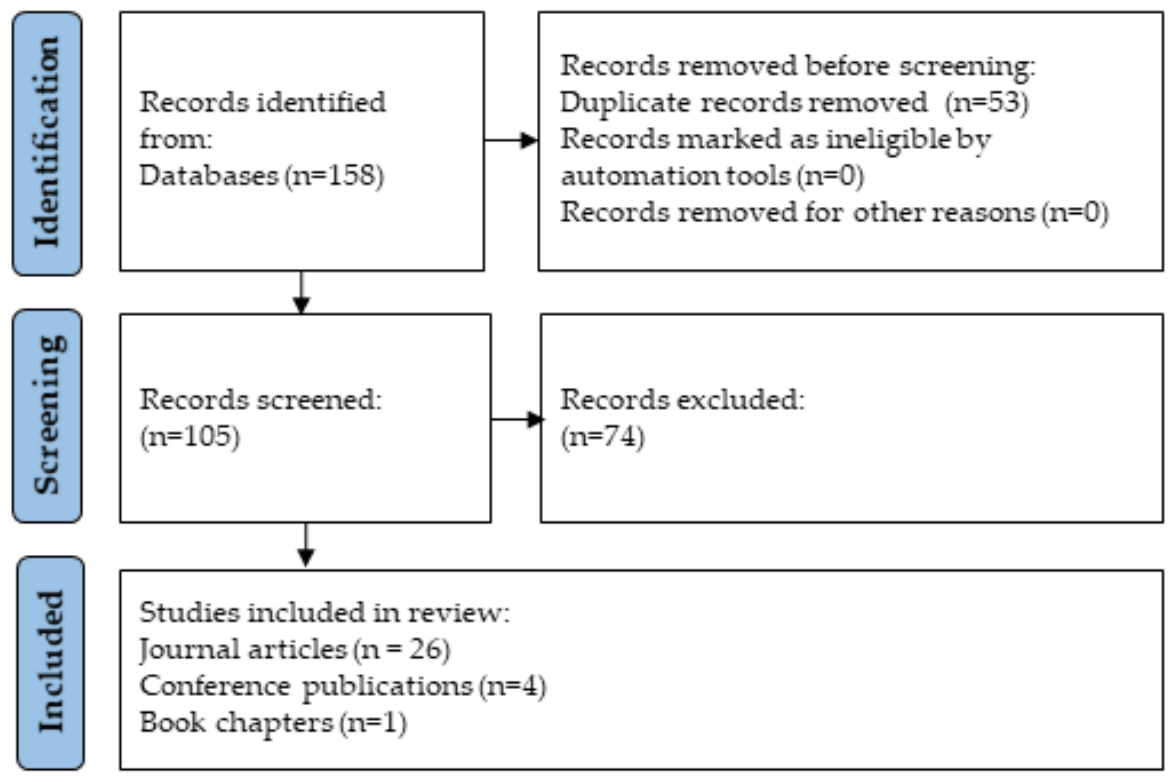

Figure 2. PRISMA flow diagram for new systematic reviews showing the number of documents obtained after each evaluation-step.

The search was limited to the published paper in the time interval January 2000 June 2021 and conducted in slightly different ways according to the internal differences among the three databases. The identification step was applied in Google Scholar, sorting the documents by relevance and considering the first three pages viewed (corresponding to the first 30 documents) having all the keywords present either in the title or in the brief subtitle description. The same was applied in Scopus, looking at the research keywords in the "Abstract, Title, Keywords" section. In Web of Science, the documents were first sorted by relevance and then selected by conducting the keywords research in the "Topic" section. Duplicates were removed. The research initially provided a total number of 158 documents, shown separately for each of the different keyword combinations in Table 1. All the included documents were written in English and available online. According to the criteria adopted in the selection of records, the keyword combinations in the considered abstract and citation databases, might not capture that do not fit any combination of the search terms. For example, the combination "Acoustic Emission" AND "Softwood" was not able to capture papers focused on the AE detection on spruce samples, if the term "Softwood" was not explicitly indicated in the keywords or in the title and abstract. However, we focused our search on papers concerning Scots pine. 
Table 1. Number of initial results obtained from Scopus, Web of Science and Google Scholar for each keyword combination.

\begin{tabular}{ccc}
\hline $\begin{array}{c}\text { Keywords } \\
\text { Combinations }\end{array}$ & Scopus + Web of Science & Google Scholar \\
\hline $\begin{array}{c}\text { Acoustic Emission } \\
\text { Grain } \\
\text { Pine }\end{array}$ & 2 & 8 \\
\hline $\begin{array}{c}\text { Acoustic Emission } \\
\text { Pine }\end{array}$ & 43 & 26 \\
\hline $\begin{array}{c}\text { Acoustic Emission } \\
\text { Softwood }\end{array}$ & 15 & 13 \\
\hline $\begin{array}{c}\text { Acoustic Emission } \\
\text { Grain } \\
\text { Wood } \\
\text { Fracture }\end{array}$ & 10 & 16 \\
\hline $\begin{array}{c}\text { Acoustic Emission } \\
\text { Earlywood } \\
\text { Latewood }\end{array}$ & 3 & \\
\hline
\end{tabular}

Step (ii) was carried out by reading 105 documents (i.e., the abstract in case of journal articles or the brief introduction in case of other type of documents, such as chapters of books or conference publications). This led to exclude 74 documents.

In step (iii), a list of 31 papers were included in the review, among them 26 articles in peer reviewed journals, 4 conference papers and 1 book chapter.

Among these 31 documents, 18 were obtained from Scopus/Web of Science (hereinafter named only as Scopus if duplicate) and 13 from Google Scholar.

\subsubsection{Analysis of Publications}

The selected documents were analysed to extract the following information:

- contents of publication;

- geographic distribution;

- year of publication;

- $\quad$ subject areas of the research (of both authors and journals).

A database was created, reporting all the relevant characteristics deduced from the content of the documents. The table was structured reporting the following information for each document: "keyword combination" used to visualise the document in the abstract and citation databases, "reference" of the document, "bibliographic ID number" used as mentioned in writing this paper, "year of publication", "authors", "affiliation" of both the first and last authors of the document, "countries" obtained from the affiliation of the first author, "topic" as the expertise of both the first and last authors, "wooden species" studied in the research, "objectives" of the research, "period of study" as the time interval in which the samples were conditioned and/or tested, "instrumentation" used in the experiments, "aspect of the grain or tree ring density" when mentioned in the document, "analysis of parameters" conducted in the research, "analysis method" applied in the works, also considering possible theoretical approaches, "case-study" indicating if the research was conducted in laboratory or in situ and "research date" on which the databases were last accessed to carry out the search. This approach allowed us to collect all the relevant information discussed in the results and discussion section of this review. The subject areas of the authors involved in the research were derived from Scopus, specifically from the profile page of the first and last authors of each document. The subject areas of the 
journals in which these documents were published were obtained from the Journal Rank Indicator SCImago. Conference publications and chapters of books were not considered in this evaluation.

\section{Results and Discussion}

\subsection{Preliminary Survey on Non-Destructive Techniques on Wooden Samples}

The preliminary survey allowed us to define the techniques mostly exploited in structural health monitoring field when dealing with wood, which are summarised in Table A2 reported in the Appendix A, divided into five categories: visual, acoustic, vibration, probing and other non-destructive techniques. The table also reports, for each technique, the type of outputs obtained in the literature.

Despite their effectiveness, NDT results are affected by several factors related to internal wood structure (grain angle), test conditions (device, sensor positioning, timber-sensor coupling mean, specimen dimensions) or environmental conditions (moisture content (MC), temperature) [6]. On these assumptions it is very important that future investigations should use unified procedures (MC adjustment factors, number of measurements, experimental and monitoring setup and procedure) to enhance the capacity of these techniques [1]. Wood grain angle was proved to be an influencing factor in the variation of wood stiffness (large grain angles can reduce stiffness and shape stability) [7]. In Cyra and Tanaka [8], wood grain angle was investigated together with the slope of grain (SoG), a parameter defined as the deviation of the grain from the edge of the wooden piece. They found that the $\mathrm{AE}$ activity in routing of yellow poplar blocks decreased from $0^{\circ}$ to roughly $15-30^{\circ}$ grain angles and reached the maximum at $150^{\circ}$. Moreover, concerning the SoG, the AE count rate (expressed in counts $/ 0.2 \mathrm{~s}$ ) gradually decreased from $0^{\circ}$ to around $75-105^{\circ}$ and reached the maximum at $180^{\circ}$.

Concerning the density parameter, it was assessed that for many softwoods, density is inversely related to tree ring width (TRW), as growth rate affects the width of the earlywood, whereas the amount of the denser latewood remains approximately constant. Therefore, TRW is included in the timber-grading criteria based on visual inspection and it is used as a rough estimate of density and thus of stiffness and strength [9]. However, probing methods are most frequently used to estimate density in existing timber structures, as the most reliable and simplest indicator of the wood mechanical properties. In addition, Lin et al. [10] studied the effects of ring characteristics on the compressive strength and established that it increased with decreasing ring width parameters and increasing ring density parameters.

\subsection{Acoustic Emission along Grain Angle Direction in High/Low Tree Ring Density of Scots Pine}

The literature review aimed to analyse and clarify the more recent information existing about the use of acoustic emission technique to monitor fracture events, occurring along the grain angle direction in Scots pine samples of low and high tree ring density.

\subsubsection{Geographic Distribution}

Figure 3 shows the map of the affiliation of the first author of the publications. Studies were performed by researchers mainly from Europe (Poland, Norway, Spain, Austria, Finland, Germany, France, Switzerland and Hungary), from Asia (Japan and China), North America (USA and Canada) and South America (only one document from Chile). The results show that the topic is especially investigated in those countries in which pine wood is more widespread in nature and hence more used as building construction material. 


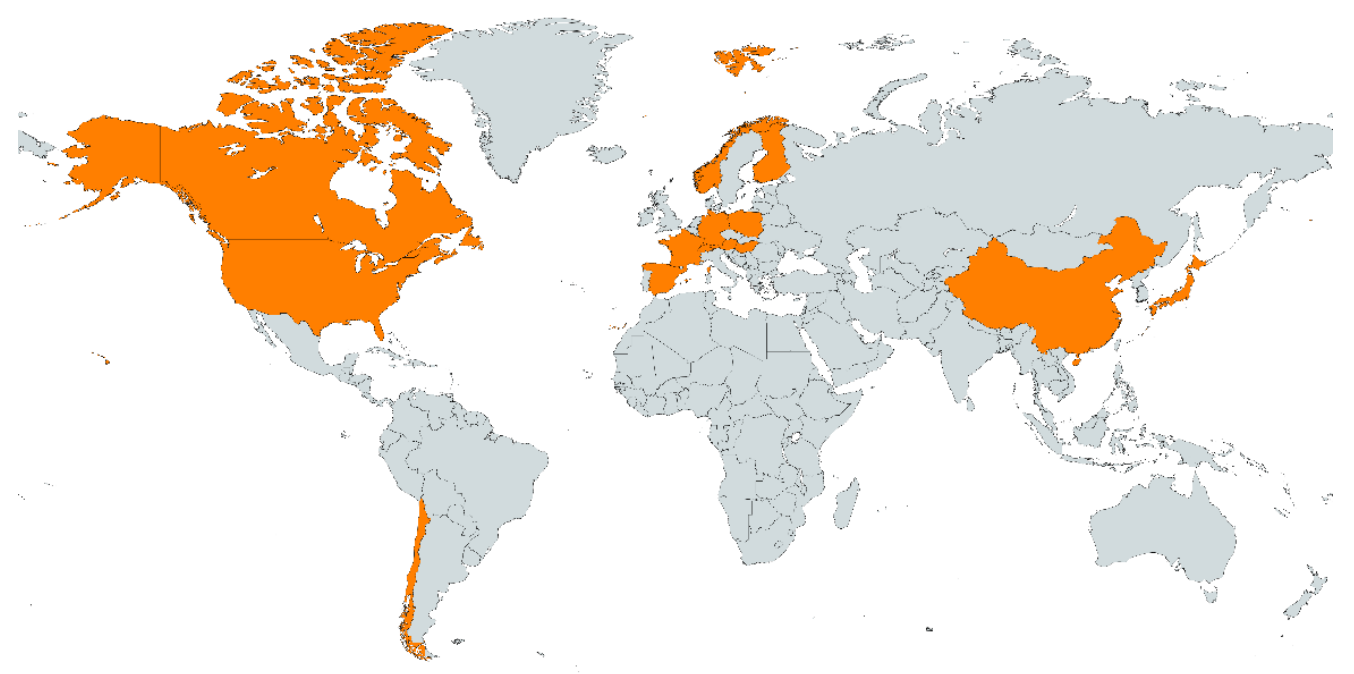

Figure 3. Geographic distribution of the first author's affiliation involved in the research topic. Created with "MapChart" (Credit: https:/ / mapchart.net/, accessed on 30 July 2021).

\subsubsection{Year of Publication}

Figure 4 shows the number of publications by year. In 2020 up to five documents were published on this specific topic.

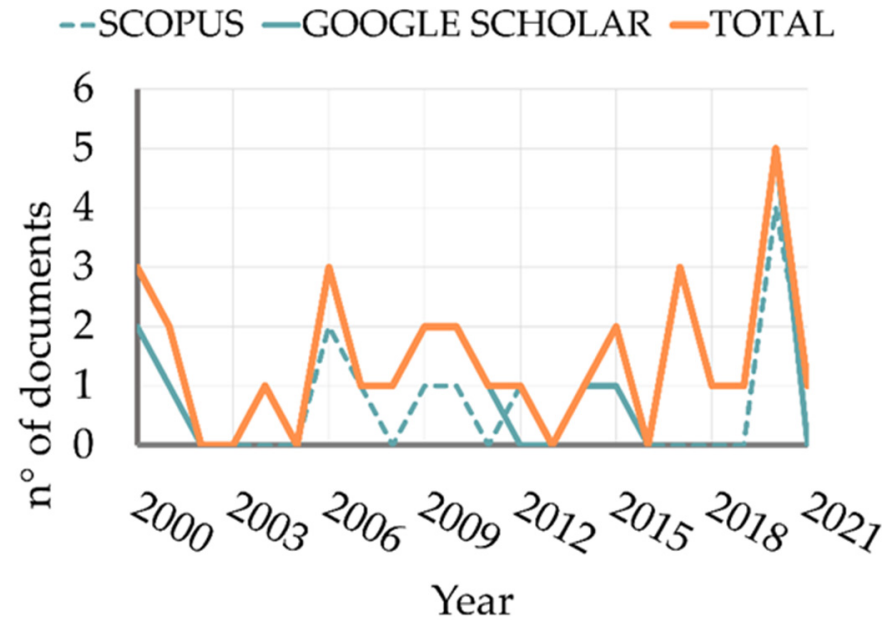

Figure 4. Number of papers by year after the refine diversified by different colours: blue dashed line for Scopus, blue solid line for Google Scholar and orange line for the total number of documents.

\subsubsection{Subject Areas of the Research}

The expertise and cultural background of both the first and last authors of each document were investigated and results are shown in Figure 5a. The authors are mainly involved in Engineering studies (33\%), then in Material Sciences studies (29\%), then in Agricultural and Biological Sciences (12\%), in Earth and Planetary Sciences (9\%) and in other disciplines including Chemistry, Computer Science, Art and Humanities, Physics and Astronomy, Energy and Environmental Science. Figure 5b shows a pie chart reporting the percentage of subject areas of the journals in which this type of research was published. The main macro-areas are Material Sciences (34\%), Engineering (24\%), Forestry (18\%), Physics $(8 \%)$ and other disciplines including Waste Management and Disposal, Agronomy and Crop Sciences, Biotechnology, Nanoscience and Nanotechnology, Plant Sciences and Metals and Alloys. 


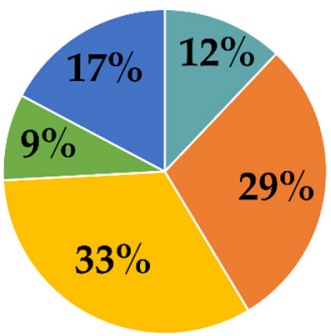

Agricultural and Biological Sciences

Materials Science

Engineering

- Earth and Planetary Sciences

- Others

(a)

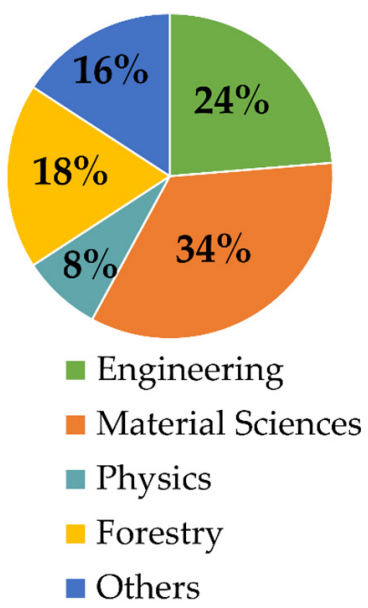

(b)

Figure 5. (a) Percentage of subject areas of expertise of the authors representing their research field and cultural background; (b) Percentage of the main subject areas of the journals.

Table 3 reports the name of the journals in which the documents were published, their corresponding main subject areas (as the macro-areas in which specific disciplines are included) and the related journal quartiles, that allow us to understand which are the most prominent journals within each specific discipline. The last column shows the number of documents published for each of the listed journals ( $\mathrm{N}^{\circ}$ of docs). Conference publications as well as chapters of books were not considered in this diagram or in the table below. Moreover, for two journals there was no detailed information available, so for this reason only 24 documents instead of 31 were included in this investigation.

Table 2. Journal's names, corresponding main subject areas, journal's quartile and number of published documents for each journal.

\begin{tabular}{|c|c|c|c|}
\hline Journal & Subject Area & Quartile & $\mathbf{N}^{\circ}$ of Doc \\
\hline Archives of Civil Engineering & Engineering & Q4 & 1 \\
\hline Bioresources & $\begin{array}{c}\text { Engineering } \\
\text { Waste Management and Disposal }\end{array}$ & $\begin{array}{l}\text { Q3 } \\
\text { Q3 }\end{array}$ & 1 \\
\hline Construction and Building Materials & $\begin{array}{l}\text { Engineering } \\
\text { Materials Sciences }\end{array}$ & $\begin{array}{l}\text { Q1 } \\
\text { Q1 }\end{array}$ & 3 \\
\hline European Journals of Wood and Wood Products & ForestryMaterial Sciences & $\begin{array}{l}\text { Q2 } \\
\text { Q2 }\end{array}$ & 1 \\
\hline Folia Forestalia Polonica-Forestry & Forestry & Q2 & 1 \\
\hline Holzforschung-Wood research and Technology & $\begin{array}{c}\text { Forestry } \\
\text { Material Sciences }\end{array}$ & $\begin{array}{l}\text { Q4 } \\
\text { Q4 }\end{array}$ & 2 \\
\hline $\begin{array}{c}\text { Insight-Non-Destructive Testing and Condition } \\
\text { Monitoring }\end{array}$ & $\begin{array}{c}\text { Engineering } \\
\text { Material Sciences } \\
\text { Metals and Alloys }\end{array}$ & $\begin{array}{l}\text { Q3 } \\
\text { Q3 } \\
\text { Q3 }\end{array}$ & 1 \\
\hline $\begin{array}{l}\text { Journal-Faculty of Agriculture Kyushu } \\
\text { University }\end{array}$ & $\begin{array}{l}\text { Agronomy and Crop Sciences } \\
\text { Biotechnology }\end{array}$ & $\begin{array}{l}\text { Q4 } \\
\mathrm{Q} 4\end{array}$ & 1 \\
\hline Journal of Material Science & $\begin{array}{l}\text { Material Sciences } \\
\text { Engineering }\end{array}$ & $\begin{array}{l}\text { Q2 } \\
\text { Q1 }\end{array}$ & 1 \\
\hline Journal of Tropical Forest Science & Forestry & Q3 & 1 \\
\hline Journal of Wood Science & Material Sciences & Q3 & 1 \\
\hline
\end{tabular}


Table 3. Journal's names, corresponding main subject areas, journal's quartile and number of published documents for each journal.

\begin{tabular}{|c|c|c|c|}
\hline Journal & Subject Area & Quartile & $\mathbf{N}^{\circ}$ of Doc \\
\hline \multirow{4}{*}{ Material Science and Engineering } & Physics & Q1 & \multirow{4}{*}{1} \\
\hline & Material Sciences & Q1 & \\
\hline & Engineering & Q1 & \\
\hline & Nanoscience and Nanotecnology & Q1 & \\
\hline Forests & Forestry & Q1 & 1 \\
\hline \multirow{2}{*}{ Materials } & Physics & Q2 & \multirow{2}{*}{2} \\
\hline & Material Sciences & Q2 & \\
\hline Physical Review Letters & Physics & Q1 & 1 \\
\hline \multirow{2}{*}{ Wood Research } & Forestry & Q2 & \multirow{2}{*}{1} \\
\hline & Material Sciences & Q3 & \\
\hline \multirow{4}{*}{ Wood Science and Technology } & Forestry & Q1 & \multirow{4}{*}{4} \\
\hline & Engineering & Q1 & \\
\hline & Material Sciences & Q2 & \\
\hline & Plant Sciences & Q2 & \\
\hline
\end{tabular}

\subsubsection{Content of Publication}

Figure 6 reports a scheme that summarises the main information extracted by the selected reviewed documents. As a result, 27 over 31 documents explored softwoods behaviour, especially of pine, spruce, hemlock, fir and cedar; 10 of them also explored the behaviour of hardwoods such as alder, oak, ash, poplar, chinkapin, birch and lime wood; while one document considered wood products such as medium-density fibreboard (MDF), oriented strand board (OSB), plywood and particleboard. In most cases, the AE technique appeared to be used in laboratory experiments and in only one case among the reviewed documents, it was applied for an in-situ monitoring focused on movable objects only [11]. The tests conducted on the samples were of various type (mainly fracture tests, but also tensile, cutting, coating, compressive, drying and torsional tests) and they sometimes involved an acclimatisation process (e.g., climate chamber [12-14] and laboratory chamber dryer [15]).

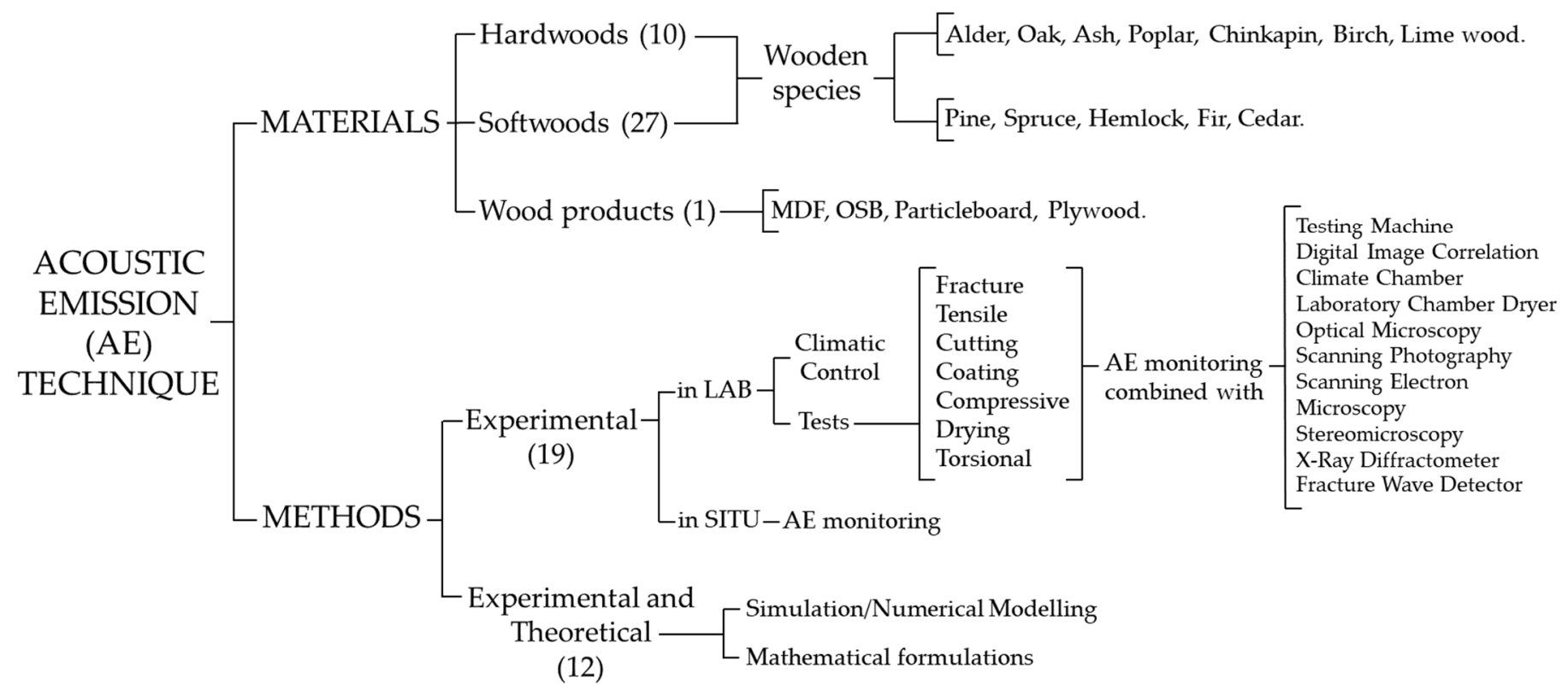

Figure 6. Information extracted from the selected documents. In these works, the Acoustic Emission technique was used alone or combined with other techniques. In brackets the number of documents. 
The acoustic emission instrumentation was often found coupled with the testing machine to perform mechanical tests and the digital image correlation often used to record images during the tests. Among the analysed documents, only 7 included microscopic observations of the surface by means of scanning photography technique, scanning electron microscopy, optical microscopy, stereomicroscopy and electron microscopy.

Finally, among the selected publications, 12 documents had both an experimental and theoretical approach, also performing numerical modelling or simulation and in some cases suggesting general mathematical formulations.

The investigation showed that the most monitored acoustic Eeission parameters were amplitude (A), energy (E) and counts (C), which were frequently studied against time, crack length and load (even in their cumulative form) with their distribution often highlighted. Among the parameters less frequently studied there are the frequency characteristics [11,16-21], other parameters such as the energy release rate $(G)[22]$, the fracture toughness $(K)[23,24]$, root mean square of the signal voltage (RMS) [25-27], density surface energy value (DSV) $[16,23]$, stress $(\sigma)$, strain $(\varepsilon)[20,28-32]$ and modulus of elasticity (MoE) [32,33].

In many cases, wood samples were subjected to pre- or ongoing experimental settings, such as acclimatisation at some temperature $(\mathrm{T})$ and relative humidity $(\mathrm{RH})$ conditions in a climate chamber or simply moistening them in water $[19,34,35]$. In more than half of these documents, the time information related to the preconditioning period was missing even when the acclimatisation setup was specified, causing a problem in the reproducibility of the experiments. The AE parameters were often related to the moisture content (MC) of the tested sample, as in the case of Rosner et al. [19] who demonstrated in their experiments that the AE count rate lower than $175 \mathrm{kHz}$ of fresh, never dried sapwood beams appeared to be much higher than that of once or twice pre-dried sapwoods. Sometimes the AE parameters were also related to the RH condition of the environment in which the tests took place. Bertolin et al. [14] carried out an investigation where the AE signals were recorded during two stages of an experimental procedure that occurred in a climate chamber at two different relative humidity levels and it was noted that the AE activity was concentrated over the first days after the hygric change and successively, as the sample equilibrated with the new environmental conditions in the chamber, it suddenly decreased. Some publications include a theoretical approach aimed to perform numerical simulation and modelling of wooden fracture behaviour, by using Finite Element Analysis through different software such as the Abaqus CAE 2019 software [23], the AutoCAD 2012 software [36], the Adina v. 8.4 Finite Element Method (FEM) program [33] and the ANSYS software package [13]. In a work by Aicher et al. [30] Linear Elastic 2D Finite Element Simulations of wood specimens were performed to obtain some insight on the most probable source region of AE signals. Nagy et al. [37] used a 2D statistical lattice model based on morphological simulations of microscopic damage evolution in wood. In some cases, comparison between experimental analysis conducted by AE and numerical modelling are presented, for example to show the capability of AE technique to monitor the crack tip growth within wood material [38].

Other works propose mathematical formulations for example as model to express the relationships between surface roughness and chip thickness [25], to compare experimental data to the theoretical ones [16], or to define the location algorithm used for the burst source location in wood specimens [30]. In Shao et al. [39] a theoretical approach was presented in the study of the fractal theory applied to examine the fracture surfaces of five types of woods. In Zhao et al. [22], based on thermodynamic approach, a theoretical model for predicting crack instability was established and the model was verified by double cantilever beam (DCB) tests.

Although the multi-techniques approach used in these documents appears to be lacking in microscopic observations, they have proved to be effective in the fracture surface analysis. In addition, their efficacy when coupled with AE system was demonstrated in a work by Kossakowski et al. [33], where a scanning photography technique made it possible to distinguish fracture patterns at different magnification, both in radial-longitudinal 
(RL) and tangential-longitudinal (TL) orientations; or in Niemz et al. [32] who used a stereomicroscope to study the fracture characteristics of different wood products. In other works, the scanning electron microscopy system was adopted [13,18,39-41], as in the case of Shao et al. [39] who used it to identify different modes of wood fracture during three-point bending tests of samples.

A few documents investigated the influence of the grain angle on the AE activity monitored on wood samples [25,29]. Aguilera et al. [25] in their studies identified changes in cutting conditions and surface quality of Scots pine samples. It was assessed that the effect of changing the slope of grain was reflected by a significant variation in the acoustic emission signals. The failure process of red Iauan and Sitka spruce specimens under static and fatigue torsional loading with different grain angle rotations was monitored by Chen et al. [29] and important differences in AE counts for hardwood and softwood were found. It was assessed that the test-piece grain angle influences the total AE counts, up to the fracture. As a result, AE counts decrease as the grain angle increases from 0 to 45 degrees and increase as the grain angle increases from 45 to 90 degrees.

The tree ring density property has also been investigated in some publications, for the way it can influence the variation of AE parameters [12,19]. Rosner et al. [19] in their experiments found that spruce latewood emitted much more AE at a given volume, because the tracheid number was higher than in spruce earlywood. This was proved by the AE count rate that appeared to be generally higher in latewood. Perrin et al. [12] highlighted in their work that wood species having a significant difference in the density values between latewood (LW) and earlywood (EW), are more likely subjected to stress concentrations at the EW/LW interfaces. It was proved that when the differences between EW and LW density values are very small, the damage mechanisms are quickly initiated but evolve progressively until the rupture (the signals are numerous but not very energetic).

\section{Conclusions}

This literature review has investigated the role that the grain angle direction and the high/low tree rings density have in detecting acoustic emission burst on Scots pine. Very few documents have analysed the relationship between these two parameters and the acoustic emission detection. Nonetheless, results provided a basis for four potential future research lines that are highlighted here:

- The AE activity emitted by wooden samples and assets under stress with different grain angle direction and tree ring density, can be investigated to assess if these two parameters might become fingerprints useful in forecasting mechanical decay. Such research might be used in the monitoring of structural health of wooden building envelopes, thus assuming a crucial role in the preventive conservation of them from mechanical stresses. In addition, such analysis might open interesting perspectives to investigate the influence of moisture content (MC) in the simultaneous assessment of mechanical and biological risk of decay on wooden samples. In fact, the MC variation is strictly related to drying/wetting events (i.e., risk of mechanical decay) while high MC provides optimal conditions for mould growth on wooden substrate (i.e., risk of biological decay).

- $\quad$ Future studies could investigate the relationship between AE activity and the tree rings density and the grain angle in pine samples (as widely used building constructions materials), to obtain insights on the durability of pine materials, leading to a higher and prompt capability to address appropriate retrofitting interventions in wooden historical buildings in the era of climate change.

- The multi-technique approach used in these documents proved to be lacking in microscopic observations, but in view of their efficacy in obtaining helpful information, it is suggested to consider the microscopy techniques in fractography i.e., in the study of the fracture surface of wood during the experimental tests.

- Finally, the information related to the preparation and acclimatisation stages of the tested samples should be improved, especially in terms of the duration of the condi- 
tioning period (an information that is often missing in the existing documents). In this way, the correct reproducibility of the experiments would be ensured.

Author Contributions: All authors equally contributed to the conceptualisation of the manuscript. All authors have read and agreed to the published version of the manuscript.

Funding: The APC was funded by CollectionCare project, which has received funding from the European Union's Horizon 2020 research and innovation programme under grant agreement $\mathrm{N}^{\circ} 814624$.

Informed Consent Statement: Not applicable.

Data Availability Statement: Raw data were generated at NTNU within the framework of the ERASMUS Students Exchange Programme and the "SyMBoL-Sustainable Management of Heritage Building in a Long-term Perspective" Project (project no. 274749) funded by the Norwegian Research Council. Derived data supporting the findings of this study are available from the corresponding author A.M.S. on request.

Acknowledgments: The authors thank the CollectionCare project (European Union's Horizon 2020 research and innovation programme under grant agreement $\mathrm{N}^{\circ}$ 814624) for the financial support of this study. The authors thank the anonymous reviewers for the constructive suggestions.

Conflicts of Interest: The authors declare no conflict of interest.

\section{Appendix A}

Table A2 summarises the non-destructive testing (NDT) techniques mainly used in structural health monitoring field when dealing with wood.

Table A1. Non-destructive techniques mainly used for timber grading and assessment of existing timber structures and their corresponding outputs.

\begin{tabular}{|c|c|}
\hline Technique & Output \\
\hline \multicolumn{2}{|c|}{ Visual techniques } \\
\hline Visual Strength Grading (VSG) & $\begin{array}{l}\text { Examination and recording of wood features, defects, signs of } \\
\text { damage or deterioration (cannot predict the influence of non-visible } \\
\text { defects; needs to be coupled with other NDT) [9]. }\end{array}$ \\
\hline \multicolumn{2}{|c|}{ Acoustic techniques } \\
\hline Acoustic Emission (AE) & Identification of the onset time of crack nucleation [42]. \\
\hline Micro Hammer (IML) & Estimation of modulus of elasticity (MOE) [1]. \\
\hline Ultrasound and stress wave & $\begin{array}{c}\text { Estimation of modulus of elasticity (MOE), dynamic modulus of } \\
\text { elasticity (Edyn) and bending strength (MOR). Assessment of } \\
\text { strength and stiffness [1]. }\end{array}$ \\
\hline \multicolumn{2}{|c|}{ Vibration techniques } \\
\hline $\begin{array}{l}\text { Portable Lumber Grader (PLG)-also coupled with } \\
\text { microphone }\end{array}$ & $\begin{array}{l}\text { Estimation of modulus of elasticity (MOE) and bending strength } \\
\text { (MOR) [1]. }\end{array}$ \\
\hline $\begin{array}{l}\text { Mechanical Timber Grader (MTG)-also coupled with } \\
\text { accelerometer }\end{array}$ & $\begin{array}{l}\text { Estimation of modulus of elasticity (MOE) and bending strength } \\
\qquad(\mathrm{MOR})[1] .\end{array}$ \\
\hline \multicolumn{2}{|c|}{ Probing techniques } \\
\hline Resistography & $\begin{array}{c}\text { Estimation of defects such as knots, fissures, decay or even termite } \\
\text { attack existing in hidden surfaces. Estimation of density (abnormal } \\
\text { density variations associated with mass loss, caused by biological } \\
\text { degradation), mechanical strength, modulus of elasticity (MOE) } \\
\text { and water content of timber }[1,9,43] \text {. }\end{array}$ \\
\hline Pylodin & Estimation of density $[1,44]$. \\
\hline Screw Withdrawal Resistance Meter (SWRM) & Estimation of density $[1,44]$. \\
\hline
\end{tabular}


Table A2. Non-destructive techniques mainly used for timber grading and assessment of existing timber structures and their corresponding outputs.

\begin{tabular}{|c|c|}
\hline Technique & Output \\
\hline \multicolumn{2}{|c|}{ Other ND techniques } \\
\hline Acoustic tomography & Study of the influence of pith distance on velocity [1]. \\
\hline Ground penetrating radar (GPR) & Assessment of the variation of the Moisture Content [1]. \\
\hline Infrared thermography (IRT) & $\begin{array}{l}\text { Species recognition, physical properties prediction and evaluation } \\
\text { of degradation level. Detection of MC differences }[1,45] \text {. }\end{array}$ \\
\hline Near Infrared-hyperspectral imaging & Determination of the ratio of juvenile wood to mature wood [1]. \\
\hline Thermal Imaging techniques & $\begin{array}{l}\text { Display the origin of crack nucleation and its progress. In static } \\
\text { torsional testing of wood, the temperature change produced by } \\
\text { thermal radiation will decrease a little when a sample is loaded but } \\
\text { increase quickly after cracking takes place. The thermal imaging of } \\
\text { softwood indicated that earlywood exchanged more thermal energy } \\
\text { than latewood [42]. }\end{array}$ \\
\hline Stress-wave Toc Tomography & $\begin{array}{l}\text { Detection of decay and defect in the interior of the wood material } \\
\text { (including knots of little size) }[45,46] \text {. }\end{array}$ \\
\hline CdZnTe-Based X-ray Spectrometer & Determination of absolute density [47]. \\
\hline Microwave-focused beam & $\begin{array}{l}\text { Detection of grain angle for arbitrary grain inclination in 3D } \\
\text { space [7]. }\end{array}$ \\
\hline $\begin{array}{l}\text { Synchrotron radiation micro-computed Tomography } \\
\qquad(\mathrm{SR} \mu \mathrm{CT})\end{array}$ & $\begin{array}{l}\text { Detection of the microscopic structure of wooden specimens under } \\
\text { initial, crack evolution and final fracture development [48]. }\end{array}$ \\
\hline
\end{tabular}

\section{References}

1. Llana, D.F.; Íñiguez-González, G.; Díez, M.R.; Arriaga, F. Nondestructive Testing Used on Timber in Spain: A Literature Review. Maderas Cienc. Y Tecnol. 2020, 22, 133-156. [CrossRef]

2. Baensch, F. Damage Evolution in Wood and Layered Wood Composites Monitored in Situ by Acoustic Emission, Digital Image Correlation and Synchrotron Based Tomographic Microscopy. Ph.D. Thesis, ETH Zürich, Zürich, Switzerland, 2015.

3. Ross, R.J. Nondestructive Evaluation of Wood, 2nd ed.; General Technical Report FPL-GTR-238; USDA, Forest Service, Forest Products Laboratory: Madison, WI, USA, 2015.

4. Zobel, B.J.; Jett, J.B. The Importance of Wood Density (Specific Gravity) and Its Component Parts. In Genetics of Wood Production; Springer: Berlin/Heidelberg, Germany, 1995; pp. 78-96.

5. Page, M.J.; McKenzie, J.E.; Bossuyt, P.M.; Boutron, I.; Hoffmann, T.C.; Mulrow, C.D.; Shamseer, L.; Tetzlaff, J.M.; Akl, E.A.; Brennan, S.E.; et al. The PRISMA 2020 Statement: An Updated Guideline for Reporting Systematic Reviews. BMJ 2021, 372, n71. [CrossRef]

6. Llana, D.F.; Íñiguez-González, G.; Esteban, M.; Hermoso, E.; Arriaga, F. Timber Moisture Content Adjustment Factors for Nondestructive Testing (NDT): Acoustic, Vibration and Probing Techniques. Holzforschung 2020, 74, 817-827. [CrossRef]

7. Bogosanovic, M.; Al-Anbuky, A.; Emms, G.W. Microwave Nondestructive Testing of Wood Anisotropy and Scatter. IEEE Sens. J. 2013, 13, 306-313. [CrossRef]

8. Cyra, G.; Tanaka, C. The Effects of Wood-Fiber Directions on Acoustic Emission in Routing. Wood Sci. Technol. 2000, 34, 237-252. [CrossRef]

9. Piazza, M.; Riggio, M. Visual Strength-Grading and NDT of Timber in Traditional Structures. J. Build. Apprais. 2008, 3, 267-296. [CrossRef]

10. Lin, C.J.; Tsai, M.J.; Lee, C.J.; Wang, S.Y.; Lin, L.D. Effects of Ring Characteristics on the Compressive Strength and Dynamic Modulus of Elasticity of Seven Softwood Species. Holzforschung 2007, 61, 414-418. [CrossRef]

11. Lukomski, M.; Strojecki, M.; Pretzel, B.; Blades, N.; Beltran, V.L.; Freeman, A. Acoustic Emission Monitoring of Micro-Damage in Wooden Art Objects to Assess Climate Management Strategies. Insight Non-Destr. Test. Cond. Monit. 2017, 59, 256-264. [CrossRef]

12. Perrin, M.; Yahyaoui, I.; Gong, X. Acoustic Monitoring of Timber Structures: Influence of Wood Species under Bending Loading. Constr. Build. Mater. 2019, 208, 125-134. [CrossRef]

13. Reiterer, A.; Sinn, G.; Stanzl-Tschegg, S.E. Fracture Characteristics of Different Wood Species under Mode I Loading Perpendicular to the Grain. Mater. Sci. Eng. 2002, 332, 29-36. [CrossRef]

14. Bertolin, C.; de Ferri, L.; Razavi, J.; Berto, F. Acoustic Emission NDT for Monitoring Hygro-Mechanical Reactions of Coated Pine Wood: A Methodological Approach. Procedia Struct. Integr. 2020, 28, 208-217. [CrossRef]

15. Jan Kowalski, S.; Smoczkiewicz, A. Acoustic Emission in Wood under Drying. Ser. B Zesz. 2004, 35, 59-71. 
16. Bertolin, C.; de Ferri, L.; Berto, F. Calibration Method for Monitoring Hygro-Mechanical Reactions of Pine and Oak Wood by Acoustic Emission Nondestructive Testing. Materials 2020, 13, 3775. [CrossRef]

17. Reiterer, A.; Stanzl-Tschegg, S.E.; Tschegg, E.K. Mode I Fracture and Acoustic Emission of Softwood and Hardwood. Wood Sci. Technol. 2000, 34, 417-430. [CrossRef]

18. Rescalvo, F.J.; Morillas, L.; Valverde-Palacios, I.; Gallego, A. Acoustic Emission in I-214 Poplar Wood under Compressive Loading. Eur. J. Wood Wood Prod. 2020, 78, 723-732. [CrossRef]

19. Rosner, S. Waveform Features of Acoustic Emission Provide Information about Reversible and Irreversible Processes during Spruce Sapwood Drying. BioResources 2012, 7, 1253-1263. [CrossRef]

20. Jakieła, S.; Bratasz, Ł.; Kozłowski, R. Acoustic Emission for Tracing Fracture Intensity in Lime Wood Due to Climatic Variations. Wood Sci. Technol. 2008, 42, 269-279. [CrossRef]

21. Diakhate, M.; Bastidas-Arteaga, E.; Pitti, R.M.; Schoefs, F. Probabilistic Improvement of Crack Propagation Monitoring by Using Acoustic Emission; Conference Proceedings of the Society for Experimental Mechanics Series; Springer: New York, NY, USA, 2017; Volume 8, pp. 111-118.

22. Zhao, Q.; Zhao, D.; Zhao, J. Thermodynamic Approach for the Identification of Instability in the Wood Using Acoustic Emission Technology. Forests 2020, 11, 534. [CrossRef]

23. Karvan, P.; Razavi, S.M.J.; Berto, F.; Bertolin, C. Energy Density and Fracture Parameters of Coated Scots Pine. Constr. Build. Mater. 2021, 290, 123206. [CrossRef]

24. Ohuchi, T.; Hermawan, A.; Fujimoto, N. Basic Studies on Fracture Toughness of Sugi and Acoustic Emission. J. Fac. Agric. Kyushu Univ 2011, 56, 99-102. [CrossRef]

25. Aguilera, A.; Vega, M.; Méausoone, P.J. Effects of Grain Angle on the Amplitudes of Acoustic Emission and Surface Roughness in Wood Machining. Wood Sci. Technol. 2007, 41, 373-381. [CrossRef]

26. Wu, Y.; Shao, Z.P.; Wang, F.; Tian, G.L. Acoustic Emission Characteristics and Felicity Effect of Wood Fracture Perpendicular to the Grain. Source J. Trop. For. Sci. 2014, 26, 522-531.

27. Landis, E.N.; Whittaker, D.B. Acoustic Emissions and the Fracture Energy of Wood. In Proceedings of the Engineering Mechanics Conference, Svratka, Czech Republic, 15-18 May 2000.

28. Mäkinen, T.; Miksic, A.; Ovaska, M.; Alava, M.J. Avalanches in Wood Compression. Phys. Rev. Lett. 2015, 115, 055501. [CrossRef]

29. Chen, Z.; Gabbitas, B.; Hunt, D. Monitoring the Fracture of Wood in Torsion Using Acoustic Emission. J. Mater. Sci. 2006, 41, 3645-3655. [CrossRef]

30. Aicher, S.; Ėfflin, L.H.; Dill-Langer, G. Damage Evolution and Acoustic Emission of Wood at Tension Perpendicular to Fiber. Eur. J. Wood Wood Prod. 2001, 59, 104-116. [CrossRef]

31. Ukyo, S.; Karube, M.; Harada, M.; Aoi, H. Damage Detection in Bolted Timber Connections Using Acoustic Emission Monitoring. In Proceedings of the 11th World Conference on Timber Engineering, Trentino, Italy, 20-24 June 2010; pp. 498-505.

32. Niemz, P.; Brunner, A.J.; Walter, O. Investigation of the Mechanism of Failure Behaviour of Wood Based Materials Using Acoustic Emission Analysis and Image Processing. Wood Res. 2009, 54, 49-62.

33. Kossakowski, P.G. Mixed Mode I/II Fracture Toughness of Pine Wood. Arch. Civ. Eng. 2009, 55, $199-227$.

34. Rice, R.W.; Phillips, D.P. Estimating the Moisture Excluding Effectiveness of Surface Coatings on Southern Yellow Pine Using Acoustic Emission Technology. Wood Sci. Technol. 2001, 34, 533-542. [CrossRef]

35. Moliński, W.; Raczkowski, J.; Muszyński, L. Acoustic Emission Generated upon Mechano-Sorptive Creep of Wood Bent across to the Grain under Asymmetrical Moistening. Holzforschung 2000, 34, 305-308. [CrossRef]

36. Rescalvo, F.J.; Rodríguez, M.; Bravo, R.; Abarkane, C.; Gallego, A. Acoustic Emission and Numerical Analysis of Pine Beams Retrofitted with FRP and Poplar Wood. Materials 2020, 13, 435. [CrossRef]

37. Nagy, E.; Landis, E.N.; Davids, W.G. Acoustic Emission Measurements and Lattice Simulations of Microfracture Events in Spruce. Holzforschung 2010, 64, 455-461. [CrossRef]

38. Diakhate, M.; Angellier, N.; Moutou Pitti, R.; Dubois, F. On the Crack Tip Propagation Monitoring within Wood Material: Cluster Analysis of Acoustic Emission Data Compared with Numerical Modelling. Constr. Build. Mater. 2017, 156, 911-920. [CrossRef]

39. Shao, Z.; Wang, F. Fractal Features and Acoustic Emission Characteristics of Wood Fracture. In The Fracture Mechanics of Plant Materials; Springer: Singapore, 2018; pp. 103-124.

40. Ando, K.; Hirashima, Y.; Sugihara, M.; Hirao, S.; Sasaki, Y. Microscopic Processes of Shearing Fracture of Old Wood, Examined Using the Acoustic Emission Technique. J. Wood Sci. 2006, 52, 483-489. [CrossRef]

41. Kánnár, A. The Effect of Moisture Content on the Micro-Damage Processes of Spruce Wood, Investigated by Acoustic Emission Method and Electron Microscopy. Acta Silv. Lign. Hung. 2006, 2, 93-104.

42. Chen, Z.; Gabbitas, B.; Hunt, D. A Thermal Imaging Technique for Studying Crack Development in Wood under Torsional Loading. J. Mater. Sci. 2005, 40, 1929-1935. [CrossRef]

43. Franco Henriques, D.; Nunes, L.; Saporiti Machado, J.; de Brito, J. Timber in Buildings: Estimation of Some Properties Using Pilodyn ${ }^{\circledR}$ and Resistograph ${ }^{\circledR}$. In Proceedings of the International Conference on Durability of Building Materials and Components, Porto, Portugal, 12-15 April 2011; pp. 1-8.

44. Osuna-Sequera, C.; Llana, D.F.; Esteban, M.; Arriaga, F. Improving Density Estimation in Large Cross-Section Timber from Existing Structures Optimizing the Number of Non-Destructive Measurements. Constr. Build. Mater. 2019, 211, 199-206. [CrossRef] 
45. Dackermann, U.; Crews, K.; Kasal, B.; Li, J.; Riggio, M.; Rinn, F.; Tannert, T. In Situ Assessment of Structural Timber Using Stress-Wave Measurements. Mater. Struct. 2014, 47, 787-803. [CrossRef]

46. Riggio, M.P.; Sandak, A.; Sandak, J. In-Situ Assessment of Structural Timber Using Stress-Wave Measurements. In Proceedings of the International Conference on Structural Analysis of Historical Constructions, Wrocław, Poland, 15-17 October 2012; Dolnośląskie Wydawnictwo Edukacyjne: Wrocław, Poland, 2012.

47. Zambelli, N.; Zanettini, S.; Benassi, G.; Bettati, A.; Zappettini, A. CdZnTe-Based X-Ray Spectrometer for Absolute Density Determination. IEEE Trans. Nucl. Sci. 2020, 67, 2273-2277. [CrossRef]

48. Baensch, F.; Zauner, M.; Sanabria, S.J.; Sause, M.G.R.; Pinzer, B.R.; Brunner, A.J.; Stampanoni, M.; Niemz, P. Damage Evolution in Wood: Synchrotron Radiation Micro-Computed Tomography (SR $\mu \mathrm{CT}$ ) as a Complementary Tool for Interpreting Acoustic Emission (AE) Behavior. Holzforschung 2015, 69, 1015-1025. [CrossRef] 